\title{
Hypocapnia and Other Ventilation-Related Risk Factors for Cerebral Palsy in Low Birth Weight Infants
}

\author{
MICHAEL P. COLLINS, JOHN M. LORENZ, JAMES R. JETTON, AND NIGEL PANETH
}

Departments of Epidemiology [M.P.C., J.R.J., N.P.] and Pediatrics and Human Development [N.P.], Michigan State University, East Lansing, Michigan 48823, U.S.A.; and Department of Pediatrics, College of Physicians and Surgeons, Columbia University, New York, New York 10035, U.S.A. [J.M.L.]

\begin{abstract}
Ventilatory management patterns in very low birth weight newborns, particularly iatrogenic hypocapnia, have occasionally been implicated in perinatal brain damage. However, such relationships have not been explored in large representative populations. To examine the risk of disabling cerebral palsy in mechanically ventilated very low birth weight infants in relation to hypocapnia and other ventilation-related variables, we conducted a population-based prospective cohort study of 1105 newborns with birth weights of 500-2000 g born in New Jersey from mid-1984 through 1987, among whom 777 of 902 survivors $(86 \%)$ had at least one neurodevelopmental assessment at age $2 \mathrm{y}$ or older. Six hundred fifty-seven of 777 assessed survivors (85\%), of whom 400 had been mechanically ventilated, had blood gases obtained during the neonatal period. Hypocapnia was defined as the highest quintile of cumulative exposure to arterial $\mathrm{PCO}_{2}$ levels $<35 \mathrm{~mm} \mathrm{Hg}$ during the neonatal period. Disabling cerebral palsy was diagnosed in six of 257 unventilated newborns $(2.3 \%), 30$ of 320 ventilated newborns without hypocapnia $(9.4 \%)$, and 22 of 80 ventilated newborns with hypocapnia $(27.5 \%)$. Two additional ventilatory risk factors for disabling cerebral palsy were found-hyperoxia and prolonged duration of ventilation. In a multivariate analysis, each of the
\end{abstract}

\section{ABSTRACT}

three ventilatory variables independently contributed a $2-$ to 3 -fold increase in risk of disabling cerebral palsy. These risks were additive. Although duration of mechanical ventilation in very low birth weight newborns likely represents severity of illness, both hypocapnia and hyperoxia are largely controlled by ventilatory practice. Avoidance of arterial $\mathrm{PCO}_{2}$ levels $<35 \mathrm{~mm}$ $\mathrm{Hg}$ and arterial $\mathrm{Po}_{2}$ levels $>60 \mathrm{~mm} \mathrm{Hg}$ in mechanically ventilated very low birth weight infants would seem prudent. (Pediatr Res 50: 712-719, 2001)

CBF, cerebral blood flow

Abbreviations

CHCE, cumulative hypocapnia exposure

CHOE, cumulative hyperoxia exposure

CI, confidence interval

CP, cerebral palsy

DCP, disabling cerebral palsy

GA, gestational age (at birth)

$\mathrm{PaCO}_{2}$, arterial $\mathrm{PCO}_{2}$

$\mathrm{PaO}_{2}$, arterial $\mathrm{PO}_{2}$

PVL, periventricular leukomalacia

VLBW, very low birth weight
The successes of neonatal intensive care during the past two decades in reducing neonatal mortality have not been matched by success in reducing the risk of $\mathrm{CP}$ and other neurodevelopmental disorders. The population prevalence of $\mathrm{CP}$ has changed little in developed countries during the past three decades (1-7).

$\mathrm{CP}$ has generally been thought to be caused by antepartum or intrapartum factors. But some recent studies in low birth weight infants have focused on the relationship of components of neonatal intensive care, particularly the management of

Received July 12, 2000; accepted June 1, 2001.

Correspondence and reprint requests: Michael P. Collins, MD, Department of Epidemiology, Michigan State University, 4660 South Hagadorn, Suite 600, East Lansing, MI 48823, U.S.A.; e-mail: didjdoctor@pol.net

Supported by grant HS-08385 from the Agency for Healthcare Research and Quality. mechanical ventilation, as risk factors for brain damage. Several studies have pointed to the possibility that the iatrogenic induction of hypocapnia (low $\mathrm{PaCO}_{2}$ ) might cause brain damage, mediated via the well-established effects of hypocapnia in decreasing $\mathrm{CBF}$. Under normal circumstances, a direct monotonic relationship between $\mathrm{CBF}$ and $\mathrm{PaCO}_{2}$ and an inverse relationship of $\mathrm{CBF}$ to $\mathrm{PaO}_{2}$ provide a compensatory mechanism through which hypoxemia or hypercapnia can provoke cerebral vasodilation. However, under circumstances of artificial hypocapnia or hyperoxemia the same mechanism could result in an inappropriate reduction in $\mathrm{CBF}$.

Although some neonatologists try to avoid hypocapnia (8, 9), studies supporting such a policy have not been definitive. Studies linking hypocapnia with brain damage have generally included only small numbers of VLBW newborns, and have 
for the most part used ultrasonographic evidence of white matter damage, rather than the diagnosis of $\mathrm{CP}$, as the outcome measure of interest.

We therefore explored the association between hypocapnia and DCP in a large, population-based cohort of infants $\leq 2000$ $\mathrm{g}$ who have been the subjects of long-term follow-up. Data collected on these infants allow for an approximation of their CHCE during their first $8 \mathrm{~d}$ of life, as well as other ventilatory variables that may also contribute to risk of DCP.

This analysis was undertaken to test the hypothesis that CHCE in the first neonatal week was associated with an increased risk for DCP. In the course of evaluating possible confounding or effect-modifying factors, however, we discovered two other ventilatory factors with risks for DCP similar in magnitude to those of hypocapnia: CHOE and a duration of ventilation beyond that predicted by GA. This report also presents data relative to these two variables and their relationship to the association between DCP and hypocapnia, but we emphasize that, unlike the case for hypocapnia, their relationship to DCP was not hypothesized a priori.

\section{METHODS}

Study Population. This study was approved by the Institutional Review Board of Columbia University College of Physicians and Surgeons and the University Committee on Research in Human Subjects of Michigan State University. Written informed consent was obtained from the parents of participating children.

Between September 1, 1984, and June 30, 1987, 1105 newborns weighing 501 to $2000 \mathrm{~g}$ at birth were enrolled in a prospectively studied cohort that consisted of all live births and transported-in newborns cared for in three newborn intensive care units in central New Jersey. The cohort has been described in detail elsewhere (10). From examination of the New Jersey vital data, we know that the study population constitutes $83 \%$ of the total population of 1318 births weighing 500 to $2000 \mathrm{~g}$ born in the three-county region during this time period. Twenty-six percent of the cohort was African-American and $25 \%$ were products of multiple births. Extensive data were collected on each mother-infant pair from the mother's prenatal record, the record of her labor and delivery, the infant's hospital record, and a maternal interview soon after the delivery of her child.

Of the 1105 infants enrolled, 982 (89\%) were born in the study center, and $123(11 \%)$ were born outside the study center. One hundred sixty-seven infants died in the hospital and 37 died later, leaving 901 infants available for follow-up examination at age $2 \mathrm{y}$. Seven hundred twenty-one of these children were seen for follow-up examination at age $2 \mathrm{y}$, and an additional 56 had their age 2 neurodevelopmental status assessed by maternal interview or questionnaire.

For the purposes of this study, we focused on the 953 (86\%) infants in the sample in whom neonatal blood gas measurements had been performed within the first $8 \mathrm{~d}$ of life. Five hundred eighty-five of these 953 infants had been mechanically ventilated. One hundred fifty-five $(16.3 \%)$ died before discharge, 31 died between discharge and age $2 \mathrm{y}$, and 110 (14.3\% of survivors) were otherwise lost to follow-up. The subjects of this study were the 657 remaining infants (400 ventilated and 257 unventilated) with an examination or maternal interview at age $2 \mathrm{y}$. Ninety-three of these infants weighed $<1000 \mathrm{~g}$ at birth. Relevant characteristics of newborns from the variously sampled subgroups of the cohort are shown in Table 1 (11). Among survivors, follow-up was less likely to be accomplished with infants who were nonwhite or born outside the study center.

Neurologic Examination at Age 2 and Diagnosis of DCP. Age at assessment was $2 \mathrm{y}$ after the expected due date based on the mother's menstrual history. The examination focused on the detection of major developmental handicaps. Motor status was quantitatively assessed by a specially trained nurse or nurse-practitioner, who examined the child's motor tone, extrapyramidal movements, and tendon reflexes in all limbs and scored each on an ordinal scale. The nurse noted the preservation of primitive reflexes and obtained goniometric measurements of the range of hip abduction and extension, popliteal extension, and ankle dorsiflexion. If the nurse could not securely classify the child as free of motor disorder, the child was referred to one of four consultant child neurologists. The neurologist completed a form identical to the nurse's screening form except that goniometry was not repeated, and classification of CP by subtype (disabling or nondisabling) was recorded. Because many referred children were not seen by the child neurologist, medical records were also used, in combination with the nurse's assessment, to assign the diagnosis of CP.

$\mathrm{CP}$ was classified as disabling when, in addition to specific neurologic findings, any of the following conditions were met:

1. Inability to walk 10 steps unaided by age $2 \mathrm{y}$

2. Bayley motor score $>1$ SD lower than performance score

3. Receipt of physical therapy for motor disability

4. Receipt of surgical intervention for motor disorder

5. Use of braces or other physical assistance devices

From the 657 infants who are the subject of this review, 58 cases of DCP were diagnosed at age $2 \mathrm{y}$. Fifteen arose from the group with birth weight $<1000 \mathrm{~g}$. Reliability of the diagnosis of DCP by these criteria was recently assessed through review of a sample of 51 records from this study by six expert international reviewers. The kappa score for the discrimination of DCP from nondisabling CP and from normal averaged 0.87 across reviewers (12). The majority of children classified at age $2 \mathrm{y}$ as having DCP have been examined later, and all but one was classified at age $9 \mathrm{y}$ as having definite CP. Although no new cases of DCP have thus far been confirmed in later examinations in this cohort, a comprehensive review of the records of all children with motor difficulties at age $9 \mathrm{y}$ is currently in progress.

Neonatal Blood Gas Sampling and Assessment of Cumulative Hypocapnia and Hyperoxemia. Blood specimens for measurement of $\mathrm{PaO}_{2}, \mathrm{PaCO}_{2}$, and $\mathrm{pH}$ were taken throughout the neonatal period as a part of the clinical management of each newborn. Among ventilated newborns, the source of the blood was listed as arterial or from the umbilical artery in $89.5 \%$, capillary in $8.5 \%$, and not specified in $2 \%$, whereas among 
Table 1a. Listing of relevant newborn characteristics by sampling criteria*

\begin{tabular}{|c|c|c|c|c|}
\hline Characteristics & All study infants & Blood gases obtained & $\begin{array}{c}\text { Blood gases obtained, } \\
\text { mechanically } \\
\text { ventilated }\end{array}$ & $\begin{array}{l}\text { Blood gases obtained, } \\
\text { ventilated, survived, } \\
\text { and followed up }\end{array}$ \\
\hline $\mathrm{N}$ & 1105 & 953 & 637 & 400 \\
\hline Birth weight (g) & $1393(407)$ & $1352(400)$ & $1223(387)$ & $1308(355)$ \\
\hline Thyroxine (z score) $\dagger$ & $-1.6(1.1)$ & $-1.7(1.1)$ & $-2.1(0.9)$ & $-2.0(1.0)$ \\
\hline One-minute Apgar $\leq 3$ & $24.2 \%$ & $25.8 \%$ & $35.0 \%$ & $28.0 \%$ \\
\hline Transferred in & $10.0 \%$ & $10.3 \%$ & $11.8 \%$ & $11.3 \%$ \\
\hline Multiple gestation & $25.7 \%$ & $26.7 \%$ & $26.5 \%$ & $27.1 \%$ \\
\hline Nonwhite & $32.3 \%$ & $31.8 \%$ & $33.1 \%$ & $31.3 \%$ \\
\hline Male & $52.0 \%$ & $53.2 \%$ & $56.4 \%$ & $53.5 \%$ \\
\hline Mechanically ventilated & $58.6 \%$ & $66.8 \%$ & $100 \%$ & $100 \%$ \\
\hline Experienced labor & $72.1 \%$ & $71.4 \%$ & $71.7 \%$ & $66.8 \%$ \\
\hline
\end{tabular}

* Each listed group is a subset of the one preceding it. For continuous variables, means and SD (in parentheses) are tabulated.

$\dagger$ Initial newborn screening value, expressed in SD units below mean (Reuss et al. [11]).

$\ddagger$ Delivered vaginally, had cesarean section for complication of labor, or experienced regular painful contractions with or without cervical dilatation.

Table 1b. Listing of relevant newborn characteristics by sampling criteria*

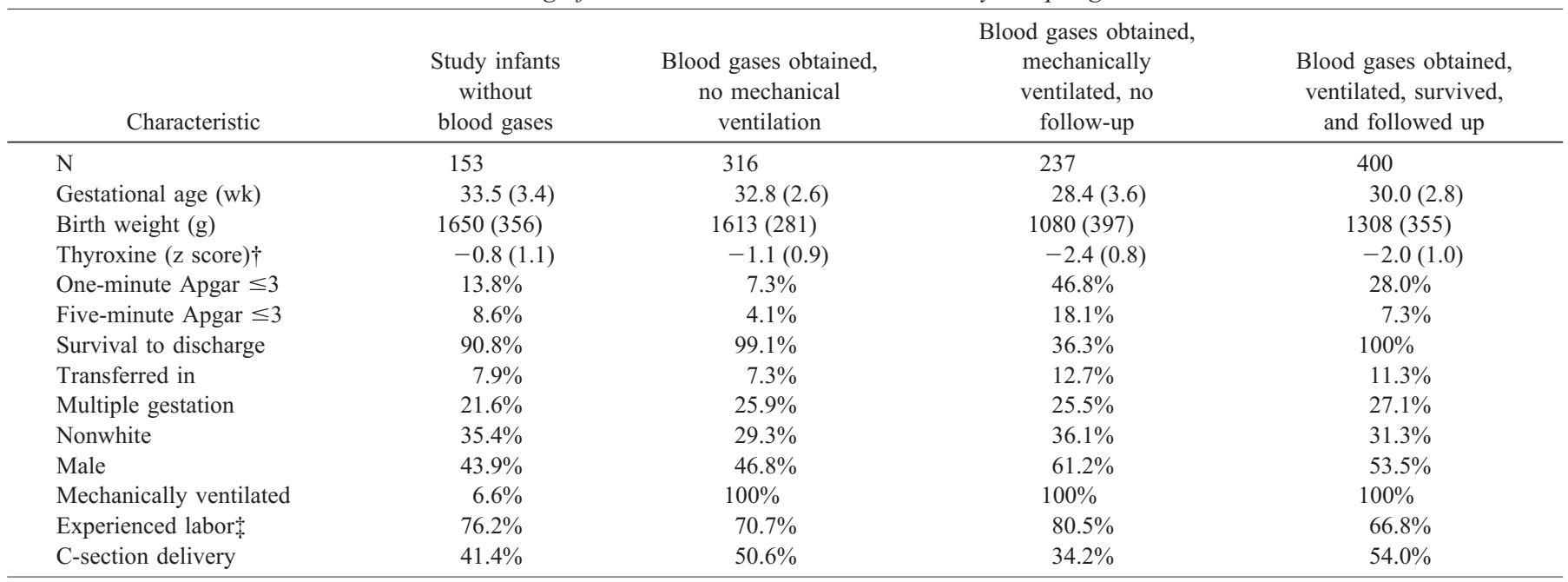

* For continuous variables, means and SD (in parentheses) are tabulated.

$\dagger$ Initial newborn screening value, expressed in SD units below mean (Reuss et al. [11]).

$\ddagger$ Delivered vaginally, had cesarean section for complication of labor, or experienced regular painful contractions with or without cervical dilatation.

unventilated newborns, the blood gas source was arterial or umbilical arterial in $62.6 \%$ and capillary in $36.7 \%$.

A $\mathrm{PaCO}_{2}<35 \mathrm{~mm} \mathrm{Hg}(4.7 \mathrm{kPa})$ has sometimes been viewed as a lower threshold for clinical management of ventilated infants. Because this figure also defined the lowest quintile of first $\mathrm{PaCO}_{2}$ in our cohort, we analyzed our data with the definition of hypocapnia as $<35 \mathrm{~mm} \mathrm{Hg}$. Similarly, clinical practice has sometimes used $60 \mathrm{~mm} \mathrm{Hg}$ as an upper threshold for $\mathrm{PaO}_{2}$. We thus define hyperoxemia here as $>60 \mathrm{~mm} \mathrm{Hg}$.

Although the exact time at which blood gases were drawn was not recorded, the recording of infant measurements was divided into intervals defined by the performance of cranial ultrasound examinations, whose timing was recorded. Thus, the intervals between blood gas measurements could be approximated for each infant. The first ultrasonographic scan was performed at a median age of $5 \mathrm{~h}$, with the interquartile range 2-9 h. A second scan was performed at a median age of $24 \mathrm{~h}$, interquartile range $23-27 \mathrm{~h}$. All blood gas measurements ob- tained before the second scan were recorded for each infant, and after this time, daily highest and lowest values for each blood gas measurement were recorded for the next week of life. Surviving ventilated infants had a median of 18 recorded blood gas measurements. For each sample, during the first $8 \mathrm{~d}$ of life in which the $\mathrm{PaCO}_{2}$ was $<35 \mathrm{~mm} \mathrm{Hg}$, the difference $\left(35-\mathrm{PaCO}_{2}\right)$ was multiplied by the time interval in hours for which that measurement was extrapolated to apply. The sum of such products for each infant constituted what we term the CHCE. In units of millimeters of mercury times hours, CHCE ranged from 0 to $>1200 \mathrm{~mm} \mathrm{Hg} \cdot \mathrm{h}$, with a mean and median in ventilated infants of 204 and $142 \mathrm{~mm} \mathrm{Hg} \cdot \mathrm{h}$, and in unventilated infants of 40 and $0 \mathrm{~mm} \mathrm{Hg} \cdot \mathrm{h}$.

A similar calculation was performed for $\mathrm{PaO}_{2}$, multiplying $\left(\mathrm{PaO}_{2}-60\right)$ by the length of each time interval inclusive of a value $>60 \mathrm{~mm} \mathrm{Hg}$. The sum of such products constituted the CHOE. Again in units of millimeters of mercury times hours, CHOE ranged from 0 to $>9000 \mathrm{~mm} \mathrm{Hg} \cdot \mathrm{h}$, with mean and 
median in ventilated infants of 2368 and $1962 \mathrm{~mm} \mathrm{Hg} \cdot \mathrm{h}$, and among unventilated infants of 530 and $208 \mathrm{~mm} \mathrm{Hg} \cdot \mathrm{h}$. The Pearson correlation coefficient relating $\mathrm{CHCE}$ and $\mathrm{CHOE}$ was 0.44 .

We calculated the severe portion of CHCE by calculating as above, but using a threshold of $20 \mathrm{~mm} \mathrm{Hg}(2.7 \mathrm{kPa})$ rather than $35 \mathrm{~mm} \mathrm{Hg}$. Severe CHCE ranged from 0 to $132 \mathrm{~mm} \mathrm{Hg} \cdot \mathrm{h}$ among ventilated newborns; only 60 of 400 subjects had been subjected to periods of severe hypocapnia by this definition. Moderate CHCE then was calculated as CHCE minus severe CHCE, i.e. intensity and duration of $\mathrm{PaCO}_{2}$ levels of $20-35 \mathrm{~mm}$ $\mathrm{Hg}$.

Relationships of membership in the upper quintile of CHCE with other possible causes of DCP are noted in Table 2 (13). We accounted for the possibility of confounding owing to these causes by including them with the primary exposures in multivariate logistic regression models.

Statistical Methods. Baseline characteristics of groups of newborns were compared using a $\chi^{2}$ test for categorical variables and a $t$ test for continuous variables. Odds ratios with confidence levels for categorical variables were calculated using the "Statcalc" procedure in Epi-Info 6.02 (Centers for Disease Control and Prevention (CDC), U.S.A., and World Health Organization, Geneva, Switzerland). To describe the presence or absence of DCP as a function of one or more explanatory variables, either continuous, such as GA, or dichotomous, such as presence or absence of labor, logistic regression models were constructed using "proc logistic" in SAS 6.12 (SAS Institute, Cary, NC, U.S.A.). Models were chosen to examine the effect of various potential confounders on the odds ratios associated with the primary exposures.

We assumed that prolonged ventilation might be a marker for, rather than a cause of, brain injury. As duration of venti-

Table 2. Characteristics of ventilated newborns $(N=400)$ exposed and not exposed to the highest quintile of cumulative hypocapnia*

\begin{tabular}{lcc}
\hline \multicolumn{1}{c}{ Characteristics } & Quintiles 1-4 & Quintile 5 \\
\hline $\mathrm{N}$ & 320 & 80 \\
Gestational age & $30.2(2.8)$ & $29.2(3.0) \|$ \\
Birth weight & $1347(353)$ & $1150(324) \|$ \\
Thyroxine† & $-2.0(0.9)$ & $-1.9(1.1)$ \\
One-minute Apgar $\leq 3$ & 37.5 & $25.6 \|$ \\
Five-minute Apgar $\leq 3$ & 8.7 & 6.9 \\
Ventilation duration (d) & $10.7(16.4)$ & $15.7(18.8) \|$ \\
Transferred in to NICU & $9.1 \%$ & $20.0 \% \|$ \\
Multiple gestation & $28.8 \%$ & $20.3 \%$ \\
Nonwhite & $30.2 \%$ & $35.9 \%$ \\
Male newborn & $55.0 \%$ & $44.3 \%$ \\
Experienced labor & $63.6 \%$ & $79.2 \% \|$ \\
C-section delivery & $55.9 \%$ & $46.3 \%$ \\
Cumulative hyperoxemia $\$$ & $13.7 \%$ & $45.0 \% \|$ \\
Prolonged ventilation & $21.9 \%$ & $31.2 \%$ \\
\hline
\end{tabular}

* For continuous variables, means (SD) are listed.

$\dagger$ Initial newborn screening value, expressed in SD units below mean (Wilson et al. [13]).

$\ddagger$ Delivered vaginally, had cesarean section for complication of labor, or experienced regular painful contractions with or without cervical dilatation.

$\S$ Highest quintile of $\mathrm{CHOE}$.

I Duration of ventilation beyond that predicted by GA.

$\| p<0.05$ for difference between groups.

Abbreviation: NICU, neonatal intensive care unit. lation was related to GA (Pearson correlation coefficient, -0.36 ), we adjusted duration of ventilation for GA by performing a linear regression analysis, among all ventilated survivors, of ventilation duration in relation to GA using "proc reg" in SAS. We then considered duration beyond that predicted by GA (predicted duration in days, $112.7-3.25 \times$ GA in weeks), if duration was $>4 \mathrm{~d}$, as a possible independent risk factor. The correlation of duration of ventilation with $\mathrm{CHCE}$ was 0.21 , and with CHOE, 0.26 .

Our measure of base excess for each infant was a timeweighted mean of base excess values calculated by a standard algorithm from blood gases obtained during the same interval for which $\mathrm{CHCE}$ and $\mathrm{CHOE}$ were calculated. Fetal growth rate was calculated as birth weight divided by the median birth weight for GA in a standard cohort (14).

\section{RESULTS}

Overall DCP Rates. The diagnosis of disabling $\mathrm{CP}$ was made in $58(8.8 \%)$ of 657 infants for whom we had both blood gas and follow-up data; 52 of the 58 cases occurred in ventilated infants.

Unadjusted Associations of DCP with Ventilation Risk Factors. The prevalence of DCP was 2.3\% (6 of 257) in unventilated and 13\% (52 of 400) in mechanically ventilated infants (odds ratio, 6.3; 95\% CI, 2.5-16.4). The rates of DCP within ventilated infants by quintile of CHCE are displayed in Table 3. Although the univariate rates show a statistically significant linear trend, when entered in a logistic regression model with other potential confounders only the rate of DCP in the highest quintile was significantly higher than that of the lowest quintile. Thus for subsequent analyses we consider an infant as "exposed to cumulative hypocapnia" if in the upper quintile of CHCE.

DCP rates within ventilated infants by quintile of $\mathrm{CHOE}$ are displayed in Table 4. As with CHCE, only the rate of DCP in the highest quintile was significantly higher than that of the lowest quintile when analyzed multivariately. We therefore consider an infant as exposed to cumulative hyperoxia if he or she was in the upper quintile of CHOE.

Associations of DCP with Ventilatory Risk Factors Taken Singly and in Combination. Rates of DCP for ventilated infants with various combinations of the primary ventilatory exposures (cumulative hypocapnia, cumulative hyperoxemia, and prolonged ventilation) are displayed in Table 5. Mechanical ventilation alone increased the odds of DCP by a factor of 2.7. This risk was not significantly added to by any of the three ventilatory exposures when these were found in isolation, although the odds ratios for hypocapnia and prolonged ventilation were both above unity when compared with ventilated infants without risk factors. When any two of the ventilatory risk exposures were present, the risk of DCP was increased about 7- to 9-fold, compared with ventilated infants with none of the risk factors. Although only 14 infants (of whom seven were $<1000 \mathrm{~g}$ birth weight) had all three ventilatory risk exposures, eight of them (five of seven weighing $<1000 \mathrm{~g}$ ) developed DCP, an odds ratio 20 times that of ventilated infants free of risk factors, and 56 times that of unventilated 
Table 3. Prevalence of DCP in ventilated newborns by quintiles of cumulative hypocapnia exposure

\begin{tabular}{ccccc}
\hline & & & Unadjusted odds ratio & Multivariate Ratio* \\
$(95 \% \mathrm{CI})$ & Reference $(1.0)$ & Reference $(1.0)$ \\
\hline Quintile & CHCE range $(\mathrm{mm} \mathrm{Hg} \cdot \mathrm{h})$ & Cases/total in group $(\%)$ & $1.1(0.3,4.5)$ & $1.1(0.3,4.3)$ \\
2 & $\leq 24$ & $5 / 81(6.2)$ & $1.9(0.5,6.8)$ & $2.0(0.6,6.8)$ \\
3 & $24-95$ & $5 / 76(6.6)$ & $2.4(0.7,8.4)$ & $2.1(0.7,6.9)$ \\
4 & $95-203$ & $9 / 82(11.0)$ & $5.8(1.9,18.6) \dagger$ & $5.3(1.7,16.2)$ \\
\hline
\end{tabular}

* Controlled for GA, fetal growth ratio, and prolonged ventilation.

$\dagger p<0.01$ compared with lowest quintile.

$\ddagger p<0.001$ for linear trend.

Table 4. Prevalence of DCP in ventilated newborns by quintiles of cumulative hyperoxemia exposure

\begin{tabular}{ccccc}
\hline & & & Unadjusted odds ratio & Multivariate Ratio* \\
$(95 \% \mathrm{CI})$ & Cases/total in group $(\%)$ & Reference $(1.0)$ & Reference $(1.0)$ \\
\hline 1 & CHCE range $(\mathrm{mm} \mathrm{Hg} \cdot \mathrm{h})$ & $3 / 80(3.75)$ & $2.5(0.5,12.5)$ & $2.0(0.5,8.2)$ \\
2 & $\leq 775$ & $7 / 80(8.75)$ & $3.3(0.8,15.8)$ & $2.4(0.6,9.4)$ \\
3 & $776-1630$ & $9 / 80(11.25)$ & $2.9(0.6,14.2)$ & $2.2(0.5,8.8)$ \\
5 & $1631-2300$ & $8 / 80(10.0)$ & $11.7(3.1,51) \dagger$ & $7.7(2.1,27.5)$ \\
\hline
\end{tabular}

* Controlled for GA, fetal growth ratio, and prolonged ventilation.

$\dagger p<0.05$ compared with lowest quintile.

$\ddagger p<0.001$ for linear trend.

Table 5. Prevalence and odds ratios for DCP by ventilatory risk factors

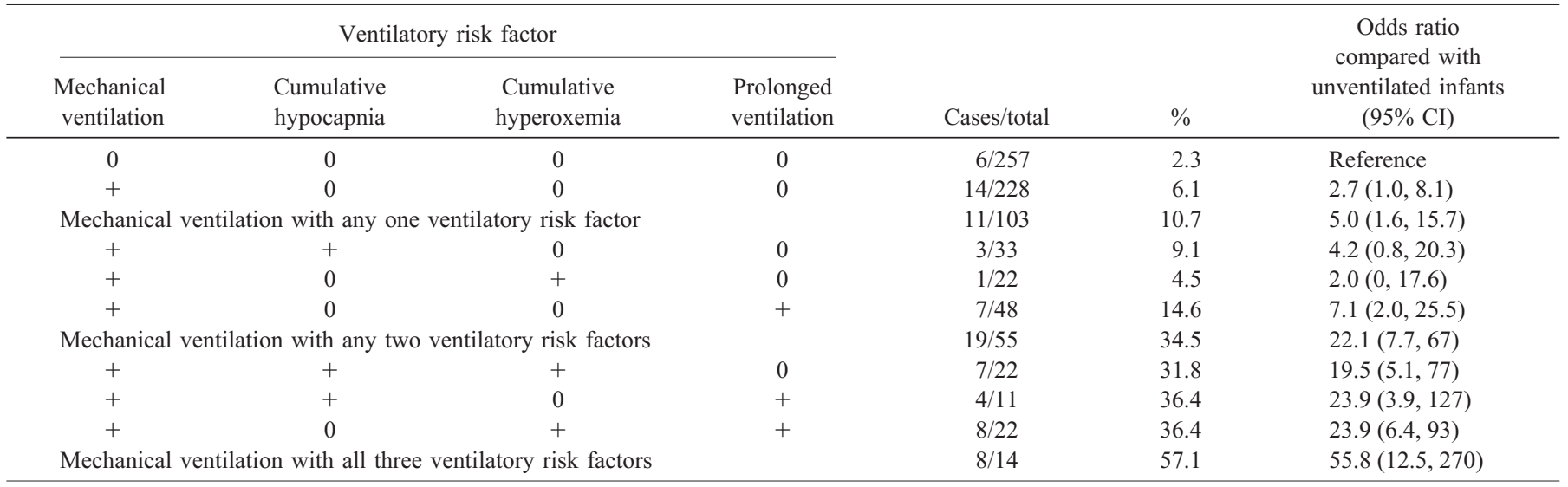

infants. The excess risks conferred by these exposures appeared to be additive; no significant interactions were found.

Of the 61 infants with DCP from the entire original study cohort, 23 arose in the 605 infants without any of the three ventilatory exposures $(3.8 \%)$, whereas 38 cases occurred among the 172 infants with at least one of these exposures $(22.1 \%)$. The population attributable risk fraction from having any combination of the three exposures is 0.51 (95\% CI, $0.36-0.67)$. This can be interpreted to mean that, if the relationships were causal, avoidance of these three exposures would reduce DCP in this population by just over $50 \%$. Similarly, the population attributable risk fraction associated with CHCE or CHOE without prolonged ventilation is 0.41 (95\% CI, 0.27-0.56).

Multivariate Analysis. We constructed a multivariate model in which we attempted to assess the unique contribution of each ventilatory exposure, adjusting for the other two as well as for other potential confounders. When only the number of blood gas samples obtained was adjusted for, cumulative hypocapnia was significantly associated with approximately a
3 -fold increase in the odds of DCP (model 1, Table 6). When hyperoxemia and prolonged ventilation were added (model 2), all three ventilatory exposures were significantly associated with DCP, each more than doubling the odds. When six correlates (in these data) of DCP are entered into the modelGA, fetal growth rate, average base excess, multiple birth status, race, and sex-the estimates of the effects of the three ventilatory exposures remain $>2.0$, although prolonged ventilation is no longer significant at the 0.05 level (model 3). The effect sizes were also not much affected by adding to the model three other potential confounders - presence of labor, transfer status, and severe hypothyroxinemia (model 4). In this most conservative model, cumulative hyperoxemia is no longer significant at the 0.05 level; thus cumulative hypocapnia is found to be the only ventilation-associated risk factor that is statistically significant regardless of the multivariate model in which it is placed, attaining a $p$ value of approximately 0.03 and a multivariate odds ratio of 2.6 (model 4 ). The multivariate odds ratio associated with an infant's having both cumulative hypocapnia and prolonged ventilation is estimated to be 8.0 
Table 6. Multivariate odds ratios for DCP with $95 \%$ CI and test of significance for risk factors

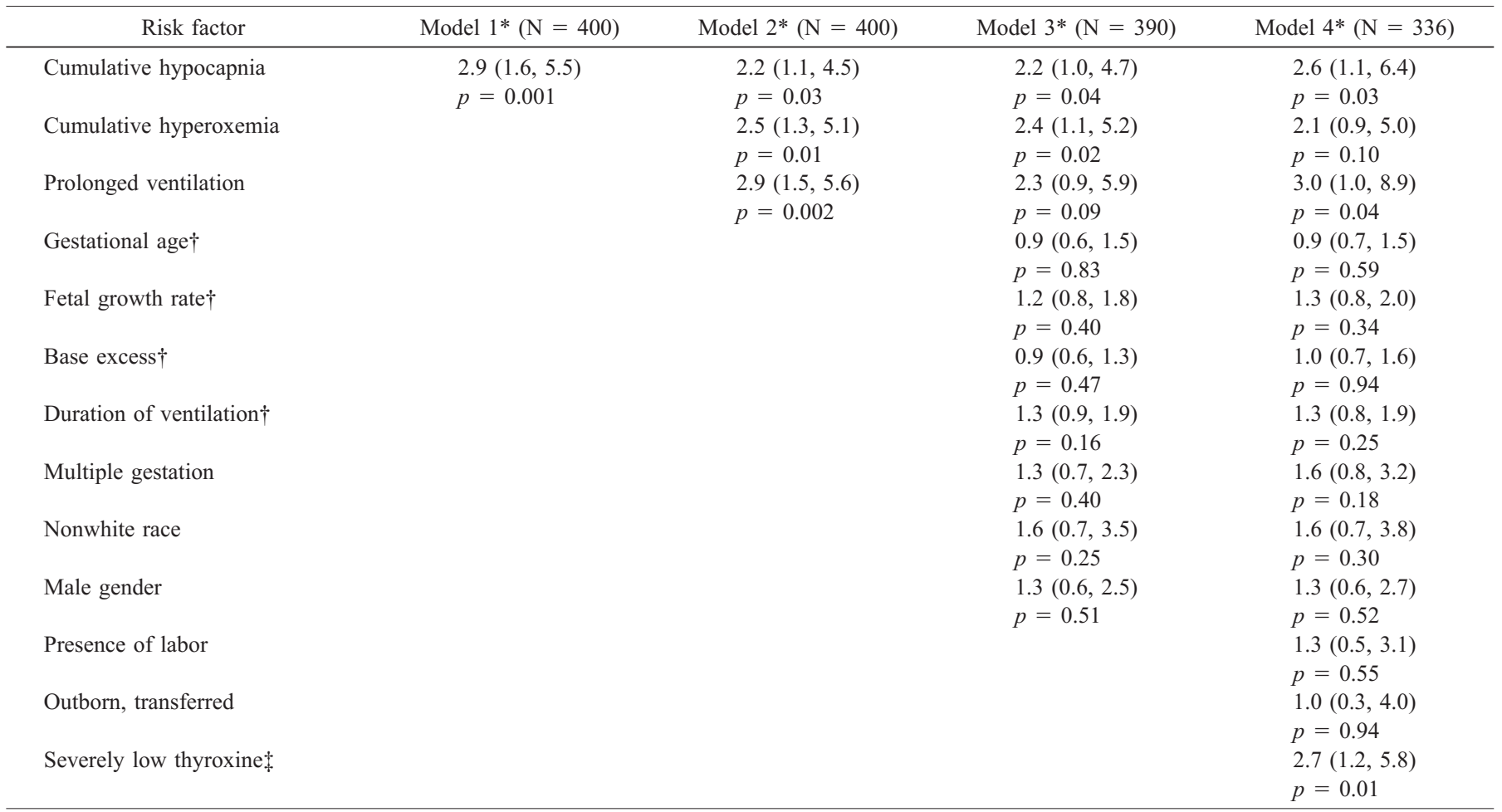

* Independent variables in logistic model 1 included cumulative hypocapnia and duration of ventilation. Model 2 added prolonged ventilation and cumulative hyperoxemia. Model 3 added GA, fetal growth rate, average base excess, multiple gestation, race, and sex. Model 4 added the presence of labor, transfer status, and severe hypothyroxinemia.

$\dagger$ Odds ratios for continuous independent variables correspond to the addition of one standard deviation to the exposure.

$\$$ Screening serum thyroxine $>2.6 \mathrm{SD}$ below the mean thyroxine level for term newborns (see Reuss et al. [11]).

(found by exponentiating the sum of the regression parameters for the two factors), and for all three factors together is estimated to be 16.5 .

Among unventilated infants (calculations not shown), neither CHCE nor CHOE was a risk factor for DCP either as a univariate predictor or in a multivariate model. Values of these variables corresponding to the upper quintile among ventilated infants did not occur in unventilated infants.

When the effect of CHCE was partitioned into that conferred by severe versus moderate CHCE (logistic regression not shown), the significant predictive power was found to reside entirely within the moderate fraction. When the effect of CHCE was partitioned into that contributed in the first $24 \mathrm{~h}$ versus the remainder of the first week of life, CHCE after the first $24 \mathrm{~h}$ explained most of the variance in DCP prevalence.

\section{DISCUSSION}

Our data show a strong relationship between exposure to a modest degree of hypocapnia and the risk of developing disabling degrees of $\mathrm{CP}$, diagnosed at age $2 \mathrm{y}$. To a slightly lesser degree, and not significantly in all multivariate models, this was found for cumulative hyperoxemia as well. Concern that hypocapnia is merely a marker for the hyperventilation response of the infants to metabolic acidosis is offset by our finding that cumulative hypocapnia is only weakly correlated with base excess (Pearson $r=0.01$ in ventilated, -0.10 in unventilated, infants). Moreover, hypocapnia does not predict
DCP in unventilated infants, and the effect of hypocapnia was unaltered by control for base excess in ventilated infants.

Our measures of exposure to cumulative hypocapnia and hyperoxemia are admittedly imprecise. The exact time of each measurement and the course of $\mathrm{PaCO}_{2}$ and $\mathrm{PaO}_{2}$ between measurements could only be approximated. However, there is no reason to believe that the degree or direction of error differed in infants with and without DCP, and this nondifferential measurement error is more likely to have biased our study toward the null.

Our multivariate analysis confirms that the association remains when adjusted for a number of other possible causal factors for DCP, including the two other ventilatory variables we explored more deeply. We cannot rule out the possibility that hypocapnia exposure might be associated with an unexamined or a yet unrecognized causal factor that confounds its relationship with DCP. Our data set, for example, contains only the clinical diagnosis of chorioamnionitis, and not the pathologic diagnosis obtainable through systematic examination of placental pathology. Thus, although adjustment for clinically diagnosed amnionitis did not alter the effects of the ventilatory risk factors (data not shown), we cannot in these data assess the effects of pathologically defined chorioamnionitis. It is difficult, however, to imagine a mechanism by which infection would be strongly linked to the cumulative exposure to hypocapnia, a requisite for confounding of the association with DCP. 
Cumulative hypocapnia could be confounded by overall severity of disease, were this category correlated with duration of ventilation, but we controlled for the number of blood gas values obtained or duration of ventilation in all of our multivariate analyses without eliminating the association of hypocapnia and DCP. In fact, the correlation between ventilation duration and cumulative hypocapnia is not particularly high (Pearson $r=0.21$ ).

Confounding by severity of disease might nevertheless occur if sicker infants had blood gases tested more often, as only the highest and lowest values of each day were recorded. Mechanically ventilated infants generally had blood gases sampled 4-6 times daily, however, and variation in the ability of this variable to capture hypocapnia should have been minimal. Hypocapnia is also not a marker of birth asphyxia, as it is only weakly related to first-day mean base excess among ventilated infants.

A plausible mechanism by which hypocapnia could increase the risk of DCP has been known for some decades. Work in experimental animals, as well as in human newborns, shows that $\mathrm{CBF}$ is positively associated with $\mathrm{PaCO}_{2}(15-21)$. Under normal circumstances such a mechanism could be protective against brain damage from mild to moderate asphyxia or hypotension, as both would be likely to be associated with hypercapnia and the resulting increase in CBF would appropriately deliver adequate oxygen levels to brain cells. These in vivo laboratory studies suggest, however, that artificial production of hypocapnia is likely to lead to decreased CBF at a time when the brain is vulnerable to ischemic injury.

The control of $\mathrm{CBF}$ by $\mathrm{PaCO}_{2}$ is apparently not linear, becoming less marked at very low levels of $\mathrm{PaCO}_{2}$ (19). This may possibly explain why our findings appear to be specific to moderately reduced $\mathrm{PaCO}_{2}$ levels $(20-35 \mathrm{~mm} \mathrm{Hg})$, rather than severe reductions $\left(\mathrm{PaCO}_{2}<20 \mathrm{~mm} \mathrm{Hg}\right)$. The relationship of $\mathrm{CBF}$ to $\mathrm{PaCO}_{2}$ is less marked in newborn animals than in adults $(18,22)$, and is less pronounced for flow to white matter than to other brain areas $(16,17)$. These two latter observations, although made in experimental animals, might be interpreted as casting some doubt on our posited causal pathway of hypocapnia through CBF to DCP. On the other hand, Vannucci and associates $(23,24)$, working in the immature rat, found $\mathrm{CBF}$ and cerebral glucose utilization to be better preserved in normocapnic and hypercapnic rats than in hypocapnic animals, and suggested that hypercapnia could be beneficial through such mechanisms as a generalized suppression of oxidative metabolism and a blunting of the neurotoxicity of excitatory neurotransmitters.

Although the net effect of these physiologic studies suggests a concern with moderate hypocapnia, studies on newborns to date have tended to concentrate on the effects of marked hypocapnia. Greisen et al. (25) found that three of seven infants with $\mathrm{PaCO}_{2}$ levels $<15 \mathrm{~mm} \mathrm{Hg}$ in the first $24 \mathrm{~h}$ of life experienced significant neurodevelopmental abnormalities, a rate higher than seen in two control groups. Graziani et al. (26) found $\mathrm{PaCO}_{2} \mathrm{~s}<17 \mathrm{~mm} \mathrm{Hg}$ to be associated with development of CP, and Ikonen et al. (27) found the duration of time spent with $\mathrm{PaCO}_{2}<30 \mathrm{~mm} \mathrm{Hg}$ to be a risk factor for PVL. Fujimoto et al. (28) found any $\mathrm{PaCO}_{2}<20 \mathrm{~mm} \mathrm{Hg}$ to be a risk factor for
PVL, whereas Wiswell and associates (29), using an area under the threshold variable similar to ours (but with a lower threshold for hypocapnia) found no relationship of hypocapnia to PVL. More recently Salokorpi et al. (30) explored the effect of experiencing at least two episodes of $\mathrm{PaCO}_{2}<22.5 \mathrm{~mm} \mathrm{Hg}$, finding an odds ratio for $\mathrm{CP}$ of 2.1, although significance was not attained. In a case-control study involving 26 infants $<32$ wk with PVL, Okumura et al. (31) found that the cases had been exposed to more hypocapnia. In none of these studies were cohorts larger than 300 infants studied. In the only large cohort study to date, Damman et al. (32) found among 799 $<28$-wk infants that first-day $\mathrm{PacO}_{2}$ values in the lowest quartile were predictive of white matter echolucencies, although multivariate significance was not attained.

Because the same overventilation that produces hypocapnia may also result in hyperoxemia, we assessed DCP risk in relation to measures of cumulative exposure to each. $\mathrm{PaO}_{2}$ has been found to bear a similar inverse monotonic relationship to CBF in experimental animals (33) and in adult (34) and infant humans (35) as does $\mathrm{PaCO}_{2}$. In our data hypocapnia is slightly better supported as a risk factor for DCP, by virtue of its statistical survival in all multivariate models. However, cumulative hypocapnia and cumulative hyperoxemia are correlated (Pearson $r$ coefficient $=0.44$ ), and thus each is to some extent a marker for the other. Because of this collinearity, either one of these two exposures appears as a substantially stronger risk factor when the other is not included in the same model.

The characteristic of a prolonged requirement for mechanical ventilation, beyond that predicted by GA, has emerged from our analyses as an additional risk factor for DCP. The relationship of duration of ventilation to GA was similar in our data to that found among neonates delivered in Northern California more recently (13). We initially hypothesized that because the requirement for prolonged ventilation might mark the most seriously brain-injured babies, hypocapnia would add little or no additional risk of DCP in this group. Instead, we found that the two risk factors seemed to be fairly independent of each other (Pearson $r$ for CHCE and duration of ventilation $=0.21)$ and did not interact in their effect on the risk of DCP. Prolonged ventilation could be the result of white matter damage, or could be a marker for severity of illness. Alternatively, prolonged ventilation may have exposed infants to hypocapnia beyond that recorded in our data.

The length of follow-up necessary to be certain of the DCP outcome could give rise to concern about the generalizability of our results to the modern situation, in which VLBW infants may be exposed to antenatal steroids or to neonatal surfactant therapy. Although the use of surfactant may modify the frequency of hypocapnia or hyperoxemia, there is no obvious mechanism by which the effects of these conditions on the brain should be modified. Antenatal steroids could conceivably modify these effects, if steroids affect components of the causal pathway linking the blood gas conditions with DCP.

Our study offers the strengths of its population basis, large cohort size, longitudinal follow-up, careful compilation of data on possible confounders, and ability to approximate individual exposure to moderate levels of hypocapnia and hyperoxemia. 
Our CHCE variable is a measure of both duration and degree of exposure to $\mathrm{PaCO}_{2}$ levels below the level of $35 \mathrm{~mm} \mathrm{Hg}$, a level formerly considered as quite modest hypocapnia. Our results indicate a nearly 3 -fold increase in risk for $\mathrm{CP}$ for infants experiencing the upper quintile of such exposure, when adjusted for a number of potential confounding factors.

The effect size of the ventilatory variables presented here was substantial. If the effects of cumulative hypocapnia and hyperoxia are causal, we estimate that their avoidance would reduce the risk of DCP in a population such as ours by $41 \%$. The policy of avoiding hyperoxia to minimize the risk of retinopathy of prematurity is already standard practice, and most nurseries try to avoid $\mathrm{PaO}_{2}$ levels of $\geq 70 \mathrm{~mm} \mathrm{Hg}$, while avoiding dips $<50 \mathrm{~mm} \mathrm{Hg}$. However, our study suggests that a more stringent restriction, to levels of $50-60 \mathrm{~mm} \mathrm{Hg}$, might be advisable.

A policy of permissive hypercapnia has also been recommended to decrease the risks of chronic lung disease and PVL $(8,9,36)$, but this has not yet become standard practice. Moreover, there is no consensus on what level of hypocapnia must be avoided or minimized. In this study the threshold for brain damage associated with hypocapnia was found at approximately $35 \mathrm{~mm} \mathrm{Hg}$, and we note that this effect was found in a sample that included more mature infants than did previous studies. Although it may be impractical and possibly even inadvisable to avoid any exposure at all to $\mathrm{PaCO}_{2}<35$ and $\mathrm{PaO}_{2}>60 \mathrm{~mm} \mathrm{Hg}$ in neonates requiring mechanical ventilation, the duration of such exposures can more easily be minimized.

Our findings will need to be corroborated by others before hypocapnia can be considered as clear a risk factor for $\mathrm{CP}$ as hyperoxemia is for retinopathy. In the interim, however, these findings deserve to be seen as cautionary observations that suggest that it is prudent to avoid prolonged hypocapnia, as well as prolonged hyperoxia, when this is consistent with the provision of prompt and adequate ventilatory support to premature infants.

\section{REFERENCES}

1. Hagberg B, Hagberg G, Olow I 1982 Gains and hazards of intensive neonatal care: an analysis from Swedish cerebral palsy epidemiology. Dev Med Child Neurol 24:13-19

2. Jarvis SN, Holloway JS, Hey EN 1985 Increase in cerebral palsy in normal birthweight babies. Arch Dis Child 60:1113-1121

3. Pharoah POD, Cooke T, Cooke RWI, Rosenbloom L 1990 Birthweight specific trends in cerebral palsy. Arch Dis Child 65:602-606

4. Escobar GJ, Littenberg B, Petitti D 1991 Outcome among surviving very low birthweight infants: a meta-analysis. Arch Dis Child 66:204-211

5. Stanley FJ, Blair E 1991 Why have we failed to reduce the frequency of cerebral palsy? Med J Aust 154:623-626

6. Stanley FJ, Watson L 1992 Trends in perinatal mortality and cerebral palsy in Western Australia, 1967 to 1985 . BMJ 304:1658-1663

7. Pharoah POD, Cooke T, Johnson MA, King R, Mutch L 1998 Epidemiology of cerebral palsy in England and Scotland, 1984-9. Arch Dis Child Fetal Neonatal Ed 79:F21-F25

8. Keszler M, Modanlou HD, Brudno S, Clark FI, Cohen RS, Ryan RM, Kaneta MK, Davis JM 1997 Multicenter controlled clinical trial of high-frequency jet ventilation in preterm infants with uncomplicated respiratory distress syndrome. Pediatrics 100:593-599
9. Mariani G, Cifuentes J, Carlo WA 1999 Randomized trial of permissive hypercapnia in preterm infants. Pediatrics 104:1082-1088

10. Pinto-Martin J, Paneth N, Witomski T, Stein I, Schonfeld S, Rosenfeld D, Rose W, Kazam E, Kairam R, Katsikiotis V, Susser M 1992 The central New Jersey neonatal brain haemorrhage study: design of the study and reliability of ultrasound diagnosis. Paediatr Perinatal Epidemiol 6:273-284

11. Reuss ML, Paneth N, Pinto-Martin JA, Lorenz JM, Susser M 1996 The relation of transient hypothyroxinemia in preterm infants to neurologic development at two years of age. N Engl J Med 334:821-827

12. Bishai S, Paneth N, Saigal S, Rosenbaum P, Jetton J, Lenski M, 1997 Level of inter-rater agreement in the diagnosis of disabling and non-disabling cerebral palsy. Paediatr Perinatal Epidemiol 11:A9

13. Wilson A, Gardner MN, Armstrong MA, Folck BF, Escobar GJ 2000 Neonatal assisted ventilation: predictors, frequency, and duration in a mature managed care organization. Pediatrics 105:822-830

14. Arbuckle TE, Wilkins R, Sherman GJ 1993 Birth weight percentiles by gestational age in Canada. Obstet Gynecol 81:39-48

15. Leahy FAN, Cates D, MacCallum M, Rigatto $\mathrm{H} 1980$ Effect of $\mathrm{CO}_{2}$ and $100 \% \mathrm{O}_{2}$ on cerebral blood flow in preterm infants. Am J Physiol 48:468-472

16. Cavazzuti M, Duffy TE 1982 Regulation of local cerebral blood flow in normal and hypoxic newborn dogs. Ann Neurol 11:247-257

17. Ashwal S, Dale PS, Longo LD 1984 Regional cerebral blood flow: studies in the fetal lamb during hypoxia, hypercapnia, acidosis, and hypotension. Pediatr Res 18:13091316

18. Hansen NB, Nowicki PT, Miller RR, Malone T, Bickers RG, Menke JA 1986 Alterations in cerebral blood flow and oxygen consumption during prolonged hypocarbia. Pediatr Res 20:147-150

19. Rosenberg AA 1988 Response of the cerebral circulation to profound hypocarbia in neonatal lambs. Stroke 19:1365-1370

20. Wyatt JS, Edwards AD, Cope M, Delpy DT, McCormick DC, Potter A, Reynolds EOR 1991 Response of cerebral blood volume to changes in arterial carbon dioxide tension in preterm and term infants. Pediatr Res 29:553-557

21. Harkin CP, Schmeling WT, Kampine JP, Farber NE 1997 The effects of hyper- and hypocarbia on intraparenchymal arterioles in rat brain slices. Neuroreport 8:18411844

22. Volpe JJ 1990 Brain injury in the premature infant: is it preventable? Pediatr Res 27(suppl):S28-S33

23. Vannucci RC, Towfighi J, Heitjan DF, Brucklacher RM 1995 Carbon dioxide protects the perinatal brain from hypoxic-ischemic damage: an experimental study in the immature rat. Pediatrics 95:868-874

24. Vannucci RC, Brucklacher RM, Vannucci SJ 1997 Effect of carbon dioxide on cerebral metabolism during hypoxia-ischemia in the immature rat. Pediatr Res 42:24-29

25. Greisen G, Munck H, Lou H 1987 Severe hypocarbia in preterm infants and neurodevelopmental deficit. Acta Paediatr Scand 76:401-404

26. Graziani LJ, Spitzer AR, Mitchell DG, Merton DA, Stanley C, Robinson N, McKee L 1992 Mechanical ventilation in preterm infants: neurosonographic and developmental studies. Pediatrics 90:515-522

27. Ikonen RS, Janas MO, Koivikko MJ, Laippala P, Kuusinen EJ 1992 Hyperbilirubinemia, hypocarbia and periventricular leukomalacia in preterm infants: relationship to cerebral palsy. Acta Paediatr 81:802-807

28. Fujimoto S, Togari H, Yamaguchi N, Mizutani F, Suzuki S, Sobajima H 1994 Hypocarbia and cystic periventricular leukomalacia in premature infants. Arch Dis Child Fetal Neonatal Ed 71:F107-F110

29. Wiswell TE, Graziani LJ, Kornhauser MS, Cullen J, Merton DA, McKee L, Spitzer AR 1996 High-frequency jet ventilation in the early management of respiratory distress syndrome is associated with a greater risk for adverse outcomes. Pediatrics 98:1035-1043

30. Salokorpi T, Rajantie I, Viitala J, Rita H, von Wendt L 1999 Does perinatal hypocarbia play a role in the pathogenesis of cerebral palsy? Acta Paediatr 88:571575

31. Okumura A, Hayakawa F, Kato T, Itomi K, Maruyama K, Ishihara N, Kubota T, Suzuki M, Sato Y, Kuno K, Watanabe K 2001 Hypocarbia in preterm infants with periventricular leukomalacia: the relation between hypocarbia and mechanical ventilation. Pediatrics 107:469-475

32. Damman O, Allred E, Kuban K, Van Marter L, Stewart J, Pagano M, Leviton A 2001 Hypocarbia during the first 24 postnatal hours and white matter echolucencies in newborns $\leq 28$ weeks gestation. Pediatr Res 49:388-393

33. Shinozuka T, Nemoto EM, Winter PM 1989 Mechanisms of cerebrovascular $\mathrm{O}_{2}$ sensitivity from hyperoxia to moderate hypoxia in the rat. J Cerebral Blood Flow Metab 9:187-195

34. Omae T, Ibayashi S, Kusuda K, Nakamura H, Yagi H, Fujishima M 1998 Effects of high atmospheric pressure and oxygen on middle cerebral blood flow velocity in humans measured by transcranial Doppler. Stroke 29:94-97

35. Niijima S, Shortland DB, Levene MI, Evans DH 1988 Transient hyperoxia and cerebral blood blow velocity in infants born prematurely and at full term. Arch Dis Child 63:1126-1130

36. Clark RH, Slutsky AS, Gerstmann, DR 2000 Lung protective strategies of ventilation in the neonate: what are they? Pediatrics 105:112-114 